\title{
Prevenção da indisciplina num agrupamento de escolas de Portugal
}

\author{
José Sousa Santos ${ }^{1}$ \\ ORCID: 0000-0002-7958-412X \\ João Carlos Pascoinho ${ }^{1}$ \\ ORCID: 0000-0003-0620-4250
}

\section{Resumo}

A indisciplina revela-se um conceito de difícil definição que surge invariavelmente associado ao contexto escolar. A definição de indisciplina assenta numa oposição clara ao conceito de disciplina e assume-se como uma quebra da ordem, de regras e de normas, prejudicando a prossecução e/ou alcance de um objetivo. Este estudo destina-se a analisar o fenômeno supracitado num agrupamento de escolas, nomeadamente ao nível do segundo ciclo, e verificar a adequação das medidas tomadas no combate à indisciplina. Recorreu-se a uma abordagem qualitativa, em que se pretendeu caracterizar a indisciplina no agrupamento de escolas em estudo, analisando os dados recolhidos através de um método interpretativo-qualitativo. Por meio dessa análise concluiu-se que, apesar de o agrupamento enveredar por combater o fenômeno de forma coerente com a legislação em vigor e implementar esforços para a sua erradicação, a indisciplina continua a persistir, devido a fatores internos e externos.

\section{Palavras-chave}

Indisciplina - Fatores internos e externos.

\section{Prevention of indiscipline in a cluster of schools in Portugal}

\section{Abstract}

Indiscipline appears as a concept difficult to define which is invariably linked to the context of school. The definition of indiscipline is based on a clear opposition to the concept of discipline and it is understood as a breach of order, rules, and norms, impairing the pursuit and/or achievement of an objective. This study aims to analyze the aforementioned

1- Instituto de Estudos Superiores de Fafe. Portugal. Contatos: josefernandosousasantos@gmail.com; joaopascoinho@iesfafe.pt. 
phenomenon in a cluster of schools, namely at the second cycle level, and to verify the adequacy of the measures taken to fight indiscipline. A qualitative approach was used, in which we aimed to characterize the indiscipline in the cluster of schools under study, analyzing the data collected through the interpretive-qualitative method. By means of this analysis it was possible to conclude that, despite the cluster of schools being committed to fight the phenomenon in a way consistent with the current legislation in force and despite implementing efforts to eradicate it, indiscipline continues to persist due to internal and external factors.

\section{Keywords}

Indiscipline - Internal and external factors.

A indisciplina na escola não é um problema recente, no entanto, a nova visão da escola aberta a toda a comunidade, a visibilidade e importância dadas a esse aspecto e, ainda, a sua midiatização, leva à ideia do aumento de episódios disciplinares. Segundo Amado (2001), esta contemporaneidade da indisciplina pode ser perspectivada de diversas formas. 0 autor, citando Veenan (1984) e Cavaco (1993), salienta duas das mais enfáticas. Estes dois pontos de vista são díspares e, no entanto, complementares, como se pode verificar:

\footnotetext{
A contemporaneidade da problemática pode ser perspectivada sob diversos ângulos, de que saliento dois: o que procura estabelecer uma relação de causa e efeito entre indisciplina escolar e o "pretenso fracasso das democracias" a todos os níveis; e o que foca a crescente dificuldade dos professores, em especial dos mais jovens e inexperientes, em lidar com os problemas de comportamento na aula, de tal modo que a questão é tida, por vezes, como um dos seus principais problemas. (AMAD0, 2001, p. 11).
}

De acordo com a nossa experiência profissional, na sua maioria, as escolas e agrupamentos não dispõem de mecanismos eficazes para lidar com o problema da indisciplina, utilizando formas isoladas de resolver as situações à medida que estas se sucedem, muitas vezes sem sucesso. Ou seja, são utilizadas medidas reativas e de tratamento parcelar de um problema de caráter transversal a toda a dinâmica de escola.

Os atores educativos, na sua maioria, tentam de forma geral lidar com comportamentos ligados à questão disciplinar, intentando ações de punição e responsabilização por comportamentos ocorridos, adotando assim uma perspectiva reativa de ação. No entanto, nem sempre isso é sinônimo da erradicação desse tipo de ato. Desse modo, percebendo a escola numa visão organizacional, dever-se-ão desenvolver mecanismos proativos de prevenção da indisciplina e criar ambientes propícios ao seu não aparecimento.

Também se observa que os alunos começam a revelar comportamentos desajustados no meio escolar cada vez mais cedo. Daí que se imponha o estudo do impacto das medidas exercidas pela escola e pelos docentes no tratamento dessas questões. 
Devido ao seu caráter "particularmente perturbador para a generalidade dos professores" (CARITA; FERNANDES, 1997, p. 15) e aos problemas gerados pela indisciplina nos docentes, admite-se que a indisciplina funciona como um fator condicionante do bom ambiente de convivência necessário ao sucesso do processo de ensino/aprendizagem. Fala-se do processo de ensino/aprendizagem, pois este fenômeno, integrado numa nova visão da escola, não afeta apenas o docente, mas todos os outros intervenientes no processo educativo.

Salienta-se que este artigo não se debruça apenas sobre o fenômeno confinado à sala de aula, pretende analisá-lo em contexto de escola, abrangendo um maior número de variáveis e interações e analisando um maior número de relações afetadas.

\title{
Definição(ões) de indisciplina: a diversidade do conceito
}

A indisciplina assume-se como um conceito de elevado grau de complexidade na sua definição. A maioria das tentativas de definição, de uma forma geral, remetem para uma antítese da disciplina. Antonucci e Longo (2007, p. 3), citam Farias (1979), quanto à definição do conceito disciplina:

\begin{abstract}
Disciplina vem do latim "disciplina" que significava "ensino" ou "material ensinada" [...] 0 termo deriva do verbo "discere" - aprender - que se opõe a "docere" - fazer aprender, ensinar. Há, porém, um segundo significado [...] "Disciplina" quer dizer um conjunto de regras de conduta impostas aos membros de uma coletividade, especialmente escolar ou militar, ou que alguém impõe a si próprio. [...] 0 termo significa a boa ordem na sala de aula, bem como seu treino promovido nas crianças através do preceito, exemplo, regras e sistemas de recompensa e punição. [...] Um processo que procura conseguir o domínio que cada um deve ter de si próprio e do ambiente circundante.

[...] A disciplina não seria um conjunto de proibições, regras e regulamentos, "embora tornemse necessárias algumas 'regras de base' funcionais que definam um campo para a liberdade [...]" 0 indivíduo disciplinado seria aquele que domina a si próprio e ao meio ambiente. Não é aquele submisso, psicologicamente subjugado ou coagido. [...] 0 significado antigo da palavra - "ser ensinado" ou "submeter-se às exigências da aprendizagem" [...] 0 termo significava uma escolaridade formal, uma aprendizagem, uma atividade organizada. (FARIAS, 1979, p. 27-29, apud ANTONUCCI; LONGO, 2007, p. 3).
\end{abstract}

Pinto (2014, p. 5) explora a mesma perspectiva, associando a indisciplina a uma alteração da ordem concebida, logo, como um desvio às regras necessárias, às normas, e que dificulta a prossecução e consequente alcance dos objetivos e expectativas:

[...] apura-se um conceito de indisciplina por oposição à ordem concebida, podendo haver, na opinião de alguns investigadores que se apresentam seguidamente, a ocorrência de algumas situações que impossibilitam ou dificultam o processo de ensino-aprendizagem: "uma violação de normas, de valores de prossecução de objetivos ou até de expectativas" (Rego \& Caldeira, 1998, p.88); "desordem proveniente da quebra das regras estabelecidas e/ou da perturbação ao nível do funcionamento da aula" (Estrela, 1992, p.15); “a manifestação de atos/ condutas, 
por parte dos alunos, que têm subjacentes atitudes que não são legitimadas pelo professor no contexto regulador da sua prática pedagógica e consequentemente, perturbam o processo normal de ensino-aprendizagem” (Silva \& Neves, 2004, p. 38); “oposto à disciplina ou ordem necessária às aprendizagens escolares" (Estrela, 2007, p. 24); "os comportamentos e atitudes que estes apresentam como perturbadores e inviabilizadores do trabalho que o professor pretende realizar". (JESUS, 1999, p. 31).

Estrela (2002, p. 17) afırma que o conceito de indisciplina se encontra intrinsecamente relacionado com o de disciplina e que, normalmente, é definido "[...] pela sua negação ou privação, ou pela desordem proveniente da quebra das regras estabelecidas”.

Mas, como referido anteriormente, a indisciplina em contexto escolar não é um fenômeno recente, muito pelo contrário, é um fenômeno que tem vindo a adquirir visibilidade, integrado na nova visão da escola enquanto organização e cuja abrangência tem vindo a ser alargada. Além disso, a complexidade do fenômeno, a multiplicidade de variáveis que nele intervêm e a diversidade das mesmas faz com que a sua definição seja, também ela, complexa e de dificuldade acrescida.

Esta preocupação é demonstrada por Oliveira (2009a) ao referir que uma das principais dificuldades do estudo do fenômeno da indisciplina é a grande diversidade de autores que a estuda e, consequentemente, a grande miríade de conceptualizações do tema. Oliveira (2009a) salienta, ainda, que alguns autores abordam a indisciplina como um problema, outros como um comportamento e outros como um fenômeno de aprendizagem.

Mas para compreender o conceito é necessário identificá-lo e defini-lo dentro da sua dificuldade. Segundo Carvalho e colaboradores (2016, p. 119-120) a indisciplina

[...] na escola é, provavelmente, tão antiga como a própria escola, variando em termos de características, formas, factores e contextos associados (Amado \& Freire, 2013; Espelage \& Lopes, 2013; Lopes, 2009). De facto, a indisciplina é um fenómeno complexo, que se manifesta de diferentes modos e graus de intensidade com génese em múltiplos factores de ordem social, familiar, pessoal e escolar e com consequências diversas para alunos, professores, escola e comunidade. Trata-se, pois, de um fenómeno que exige uma leitura compreensiva e holística que contemple a multiplicidade dos fatores desencadeantes e a diversidade de manifestações comportamentais associadas, bem como os modelos de intervenção integrados e sustentados na literatura científica (Amado \& Freire, 2013; Espelage \& Lopes, 2013; Lopes, 2009; Sugai \& Horner, 2002).

Por sua vez, Carita e Fernandes (1997, p. 15) referem que o conceito indisciplina assume-se como

[...] alguma coisa de particularmente perturbador para a generalidade dos professores. A indisciplina perturba os professores, afecta-os emocionalmente, mesmo mais que os problemas de aprendizagem com que habitualmente também têm de se confrontar. Mas a indisciplina mexe mais fundo, sendo frequentemente vivida como uma obstrução à relação ou mesmo como uma desconsideração pessoal ou mesmo ainda como um ataque pessoal. A indisciplina é uma situação 
em que frequentemente os professores se sentem desconsiderados, desprezados, questionados enquanto pessoas.

Carita e Fernandes (1997) encaram a indisciplina como uma realidade perturbadora para o docente e intimamente ligada à relação entre professor/aluno e às diferenças entre o estatuto de ambos.

Por último, para Amado (2001, p. 12) a indisciplina é um "[...] comportamento disruptivo em geral, enquanto perturbação e obstáculo ao bom funcionamento de uma aula”.

Como se verifıca depois da análise dessas definições, a indisciplina em contexto escolar, reveste-se de um caráter abrangente e transversal a todas as áreas, espaços e atores educativos, sendo que a sua influência é sentida por todos em diversas circunstâncias durante o processo educativo.

Em suma, e citando Amado (2001, p. 43),

[a] indisciplina é, precisamente, um dos aspectos mais "notáveis" e "observáveis" dessa vida na aula enquanto fenómeno relacional e interactivo que se concretiza no incumprimento das regras que se estabelecem, presidem e orientam as condições das tarefas na aula e, ainda, no desrespeito de normas e valores que fundamentam o são convívio entre pares e a relação com o professor enquanto pessoa e autoridade.

No documento orientador da ação da tutela, o Conselho Nacional de Educação Português define indisciplina como "todos os comportamentos que reflictam o propósito de perturbar os processos de aprendizagem que decorrem na escola, dificultando o exercício da função docente, inibindo uma efectiva cooperação discente, perturbando a convivência da comunidade educativa no seu todo" (PORTUGAL, 2002, p. 5480). Como é reconhecido pelo próprio Conselho Nacional de Educação, trata-se de uma noção de espectro largo, visando essencialmente fornecer um conceito operacional passível de incluir todas as dimensões do problema em análise.

0 enquadramento legislativo amplo da fenômeno da indisciplina nas escolas portuguesas é fornecido pelo Decreto Lei n. ${ }^{\circ}$ 51/2012 (PORTUGAL, 2012a), da Assembleia da República Portuguesa, que aprova o Estatuto do Aluno e Ética Escolar. Este decreto lei, partindo de um compromisso de toda a comunidade educativa, estabelece os direitos e os deveres do aluno dos ensinos básico e secundário. Não existindo no normativo qualquer tentativa para definição do conceito de indisciplina, o comportamento que procura evitar e, se necessário, sancionar será a falta de cumprimento dos deveres do aluno (artigo $10 .^{\circ}$ do Estatuto do Aluno e Ética Escolar) e das suas responsabilidades (Artigo $400^{\circ}$ do Estatuto do Aluno e Ética Escolar).

\section{Fatores de indisciplina}

Para compreender o fenômeno da indisciplina é imprescindível referir e caracterizar o aluno indisciplinado. Este é apenas uma criança/jovem que ainda não desenvolveu o seu conceito de autodisciplina, que ainda não tomou consciência de que o seu comportamento 
prejudica o processo de ensino/aprendizagem, quer o seu, quer o dos colegas. Este aluno não consegue adotar atitudes corretas porque ainda não desenvolveu a noção do que é o correto. 0 conceito de democracia em sociedade não é respeitado por ele, consequentemente as suas ações são irresponsáveis e inconsequentes e perturbam todo o bom funcionamento da escola e da aula, consoante o espaço físico em que suas ações decorram. Amado (2001) realça que dentro de uma perspectiva holística do ensino, uma visão completa dele deve conferir importância a fatores externos, por mais afastados que possam parecer, e a fatores internos. Dentro desta perspectiva, Amado enquadra a indisciplina como um fenômeno de interação social em que cada ator desempenha um papel preponderante no desenvolvimento ou na sua estagnação.

Também de acordo com Oliveira (2009b, p. 291), as transformações históricas, sociais e pedagógicas ao longo deste último século, "[...] interferiram nas relações dentro da escola e, consequentemente, nas atitudes dos professores, que vão interferir, também, no comportamento das crianças, prejudicando a relação professor/aluno e aluno/aluno e, por vezes, acabam culminando em indisciplina”.

Oliveira (2009b) faz uma destrinça entre dois grandes grupos de fatores, psicossociais e pedagógicos, sendo os primeiros externos à escola e os segundos intimamente ligados à sua organização. No que concerne aos fatores psicossociais, segundo a autora, podemos encontrar em primeira instância a família, ou seja, a influência que a criança recebe do núcleo a que pertence, no qual irá buscar valores, normas de conduta, entre outros fatores. No clima social atual, em que a vida da família é pautada por uma ausência temporal extrema, existe uma desresponsabilização desta na educação das crianças, sendo a tarefa de educar transferida para a escola. Também o ambiente sentido no seio das famílias e os problemas inerentes a elas ${ }^{2}$ irão influenciar a personalidade da criança, quer sejam questões como a violência ou a superproteção. ${ }^{3}$ Esses fatores são fruto da sociedade atual e da sua desintegração, que invariavelmente leva à desestruturação familiar e da própria criança.

A autora nomeia também a sociedade de informação mediatizada em que se centra a nossa vida atualmente, no enfoque nas novas tecnologias, na televisão e afıns, que transmitem valores e normas cuja pertinência as crianças não conseguem selecionar e decifrar.

De seguida, e ainda dentro desse grupo de fatores, é referida a heterogeneidade dos alunos dentro do grupo, referindo aqui o desvio de comportamento ao que o professor considera correto e que conduz a que o aluno que pratica o comportamento seja preterido em prol de outrem. Essa situação irá ressaltar uma discriminação conducente a um sentimento de injustiça pela não compreensão. 0 que é bem patente na afirmação de Oliveira (2009b, p. 294).

\footnotetext{
2- Queremos chamar a atenção, também, para o fato de que nessas famílias que se encontram desorientadas e desestruturadas muitas pessoas são alcoólatras, drogadas, violentas e, às vezes, agridem-se diante das crianças. Além de os responsáveis por cuidar e educar as crianças muitas vezes se agredirem, o pior é que a criança também é agredida por eles (OLIVEIRA, 2009b).

3- Há, também, situações opostas a essas: 0 excesso de mimos, a superproteção e a permissividade por parte dos pais/responsáveis também acarretam problemas de comportamento nessas crianças em casa e na escola. A criança educada dessa forma acha que todos estão a seu dispor para atendê-la e que não tem regras a seguir, tudo gira ao seu redor, ela é o centro das atenções (OLIVEIRA, 2009b).
} 
Esse é um fator com o qual os profissionais da educação devem se preocupar, pois, comumente, o professor não tem preparo para lidar com a diversidade e acaba determinando, às vezes inconscientemente, como aceitável o comportamento daquele aluno cujas atitudes e costumes demonstram proximidade com os seus valores, ou seja, com aquilo que ele julga ser o certo. Nesse caso, pode ocorrer que um aluno que não se enquadra no "modelo" estabelecido pelo professor passe a ser discriminado, fazendo com que o professor manifeste, mesmo que implicitamente, uma predileção por um ou outro aluno. Isso acaba prejudicando as crianças que são discriminadas, pois o professor passa a adotar tratamento diferenciado para os alunos. Essa discriminação pode ocorrer não só em relação à cultura da criança, mas também no juízo que o professor faz do aluno, seja por sua aparência, pelo modo de se comportar, seja pela forma como se expressa, pela sua dificuldade em aprender os conteúdos, e tudo isso pode causar grandes conflitos em sala de aula.

A situação descrita culmina, normalmente, numa rejeição pela organização escolar que levará o aluno a encará-la mais como um dever ou uma obrigação e menos como um direito e algo prazeroso.

Ainda dentro desse âmbito, a autora nomeia os distúrbios de atenção como um dos grandes causadores de indisciplina em contexto escolar. Essa questão prende-se com a inclusão de crianças com necessidades educativas especiais em contexto de sala de aula.

Por último, dentro do grupo de fatores em análise, a autora sublinha a importância da carência afetiva, como causadora de comportamentos passíveis de levar à indisciplina em contexto escolar, mais especificamente em sala de aula. A criança irá forçosamente tentar chamar a atenção a fim de conseguir o afeto que não tem em casa.

Por outro lado, a autora salienta ainda a existência de outro grupo de fatores, extrínsecos aos alunos e intrínsecos ao contexto escolar, como potencializadores do fenômeno da indisciplina, os fatores pedagógicos.

Dentro desse âmbito, é importante mencionar que já anteriormente Carita e Fernandes (1997, p. 24) imputavam um conjunto de fatores extrínsecos ao aluno e da responsabilidade do docente como causadores da indisciplina na sala de aula. As autoras mencionavam, assim, as características da situação de aprendizagem, salientando como principais causadoras de indisciplina as mais ambíguas ou novas, como é o caso dos primeiros dias de aula, a personalidade do modelo, nesse caso o docente, o valor do comportamento deste e o reconhecimento de mérito da parte dos alunos ao ele, e a intencionalidade e sistematicidade com que o modelo se exprime.

Mas, regressando a Oliveira (2009b, p. 298), são fatores pedagógicos, e consequentemente inerentes ao ambiente escolar e/ou ao contexto educativo, em primeira instância, a ausência ou imposição excessiva de regras, ou seja, grosso modo a organização escolar, em geral, e a maioria dos docentes, em particular, seleciona e impõe uma série de regras elaborada sem auscultação prévia dos alunos. Desse modo, estas regras não têm a colaboração dos principais destinatários na sua elaboração, revelando-se muitas vezes isentas de sentido para os mesmos.

É fundamental que os alunos tenham parte ativa no estabelecimento das regras que irão seguir, a fim de propiciar um ambiente de aprendizagem coerente com os seus ideais e pleno de sentido. 
Em segundo lugar, menciona a formação docente quanto às questões relacionais como um dos fatores deste grupo. Esta, muitas vezes, revela-se insuficiente e inadequada como demonstra abaixo:

Nos cursos de formação, a preparação do professor para os aspectos relacionais, incluindo a indisciplina, é tratada de forma superficial; muitas vezes esses cursos não alertam para a problemática da relação professor-aluno, para as causas da indisciplina e da violência que ocorrem dentro das escolas, para as formas de prevenção, e não orientam para um gerenciamento de sala de aula que envolva motivação e participação dos alunos. Uma formação voltada para uma atuação profissional mais consciente e ativa, na qual o professor deixe de ser um mero transmissor de conhecimento, poderia diminuir o problema da indisciplina dentro da sala de aula. Esse procedimento, na formação do educador, seria o que podemos chamar de medida de prevenção da disciplina, que, acreditamos, traria melhores resultados do que as medidas de correção ou punição frente às condutas já instaladas. (OLIVEIRA, 2009b, p. 300).

De seguida, a autora menciona a proposta pedagógica do professor, ou a ausência dela, como um dos fatores a se considerar no surgimento e desenvolvimento da indisciplina. Assim, a forma como o professor apresenta e leciona os conteúdos, e até o tipo de conteúdos a lecionar, deverá ir ao encontro das expectativas dos alunos sob o risco de os primeiros não lhes conferirem sentido.

Por último, o sistema educacional e a própria escola são também apontados nesse conjunto de fatores devido à forte influência das indicações superiores no que diz respeito ao sistema educacional ${ }^{4}$ e à desmotivação que daí advém. Também os espaços físicos são desagradáveis e inadequados à nova visão do paradigma de ensino.

Além disso, a inércia da organização escolar face a uma sociedade em constante mudança faz com que a frequência da escola seja considerada uma obrigação, daí que a indisciplina surja enquanto aspecto promotor de um ambiente mais adequado ao aluno.

De forma geral, os estudos efetuados sobre o assunto em epígrafe salientam a importância desses fatores na evolução da indisciplina: Banaletti e Dametto (2015, p. 4) colocam seu foco nas mudanças sociais e nas alterações que estas provocaram no modelo educacional, a nível da visão do processo de ensino/aprendizagem, da autoridade do professor e da visão da escola. Amado (2001), por exemplo, analisa separadamente cada um dos fatores, centrando-se no indivíduo em primeira instância e na sua integração no grupo, para depois se focar na escola e na educação e nas suas contribuições para o fenômeno; Rodrigues, Marques e Gomes (2012, p. 21) cita Vasconcellos a fim de sustentar:

[...] que a indisciplina é um processo que agrega muitos fatores: o desinteresse do aluno proveniente, por exemplo, da influência midiática externa ao ambiente escolar, geralmente mais atrativa que a escola; a família que não cumpre com o papel de educar para os limites; a escola que não apoia o professor pedagogicamente; e a influência da desorganização da sociedade.

4- Exemplos disso são as escolas superlotadas, as turmas numerosas, mobiliário sem condições e antiquado, falta de material didático, exigências de trabalhos burocráticos excessivos aos professores, remuneração insatisfatória, mudanças constantes de paradigmas educacionais, entre outros. 


\section{Metodologias utilizadas em diversos estudos}

De forma geral, ao observarmos os estudos sobre indisciplina verificamos que a maioria se inscreve dentro da investigação qualitativa, assentando a sua ação na situação natural e pretendendo uma descrição dos dados em detrimento da análise dos mesmos. A sua preocupação primordial centra-se no processo, no produto e no resultado final, focando a análise no particular e tentando procurar o significado. Logo, organizam a sua ação a partir de uma observação, apoiada por diversos instrumentos que a sustentem, como por exemplo entrevistas. Essa análise qualitativa é bem visível, em Amado (2001), em Banaletti e Dameto (2015) ou ainda em Pessoa (2012).

Amado (2001) apoia seu estudo na observação e na interação com os seus alunos e colegas, com os quais está intimamente ligado, registando as suas observações num bloco de campo e analisando a posteriori essas anotações.

A dificuldade de se estudar um comportamento e/ou fenômeno tão antigo como a indisciplina revela-se na exaustão de estudos sobre ele. A grande quantidade de estudos efetuados leva a que se complementem, se imiscuam, se cruzem e que também se complementem, levando a que se teça uma miríade de conclusões que nos fazem pensar que este trabalho possa ser redundante. Ainda assim, pretende-se verificar se as medidas tomadas pelo agrupamento em análise no combate à indisciplina estão interligadas com as alterações na frequência da indisciplina e avaliar se a burocracia subjacente à implementação das medidas legais impede e trava o uso dos mecanismos formais, levando a um aumento da indisciplina.

\section{Método}

A metodologia utilizada neste artigo é consistente com a maior parte dos estudos na área. 0 estudo assenta-se numa metodologia qualitativa e num método comparativo constante (BOGDAN; BIKLEN, 1994, p. 101) associado a uma abordagem interpretativo-qualitativa.

\section{Participantes}

Os participantes foram selecionados em turmas do segundo ciclo do ensino básico, ou seja, nas turmas de quinto e sexto anos de escolaridade; ciclo de ensino no qual se regista o maior número de ocorrências disciplinares dentro do agrupamento. No $5^{\circ}$ ano de escolaridade encontra-se um total de oito turmas com 203 alunos e no $6^{\circ}$ ano de escolaridade existem dez turmas com 268 alunos.

Desse elevado número de alunos, foi, a posteriori, selecionada uma amostra de alunos de cada turma, após diálogo com os diretores de turma, a fim de se proceder à realização dos grupos de discussão (seis alunos por turma, sendo que destes 50\% foram alunos com comportamentos que fogem ao conceito de indisciplina e os demais que se enquadram nele).

Fizeram também parte desta amostra os diretores de turma das turmas num total de dezessete (visto que no $6^{\circ}$ ano existe um docente com duas direções de turma) e outros 
docentes que se revelaram fundamentais para o estudo, tal como a docente encarregada da redação dos processos disciplinares.

Ainda como atores do estudo, encontramos também o diretor do agrupamento, a coordenadora dos diretores de turma e os responsáveis pela área de alunos da direção (embora estes últimos tenham sido auscultados em conversa informal).

\section{Instrumentos e procedimentos}

Foram realizadas entrevistas a vários atores educativos tendo como função principal a recolha de dados e permitir intuir acerca da forma como os atores questionados veem o fenômeno da indisciplina no agrupamento alvo de análise, como, aliás, referem Bogdan e Biklen (1994, p. 134) e Amado (2001, p. 205), citando Estrela (1984), quando menciona que a entrevista pode ser utilizada em consonância com outros métodos de investigação a fim de se poder emitir um parecer acerca da coerência dos resultados e validar os dados recolhidos através da mesma.

Desta forma, para se proceder às entrevistas estruturadas e/ou semiestruturadas, foram criados guiões orientadores. A entrevista ao diretor do agrupamento de escolas foi realizada no âmbito de uma entrevista estruturada, constituída por três módulos: o primeiro - clima da escola - pretendeu obter o ponto de vista do diretor sobre o tema e sobre os principais agentes de intervenção nele, tais como o Programa Escola Segura; no segundo módulo, pretendeu-se auscultar o diretor acerca dos comportamentos desviantes e potenciais causadores de indisciplina no agrupamento em estudo; e, por último, o terceiro módulo, estratégias de mediação, pretendeu uma elucidação por parte do diretor sobre estratégias, formação e aplicação da legislação no âmbito do combate à indisciplina.

A entrevista à coordenadora dos diretores de turma, por sua vez, já se revestiu de um caráter mais aberto e flexível, no entanto, ainda com alguma estruturação, sendo incluída no âmbito designado por semiestruturada, a fim de permitir entender qual a sua visão geral acerca de determinados aspectos tal como, por exemplo, a proatividade/ reatividade das medidas tomadas.

Por último, e dentro deste campo, também as entrevistas aos diretores de turma se revestiram de um caráter semiestruturado, permitindo, assim, que eles extrapolassem o âmbito das questões e enveredassem por alguns episódios mais marcantes no combate à indisciplina, que permitiram algumas conclusões imprescindíveis para o artigo.

A fim de se poder verificar qual a postura das estruturas intermédias do agrupamento no combate à indisciplina, procedeu-se a uma pesquisa e análise documental, nomeadamente às atas dos conselhos de turma, a fim de se verificar a existência de relatos de situações de indisciplina mais gravosa e possiveis sugestões de estratégias a implementar. Além disto, esta pesquisa revestiu-se de especial importância ao verificar quais turmas apresentaram mais situações de indisciplina naquele ano letivo e se a incidência do fenômeno se verificava de forma parcelar (em determinadas turmas) ou de forma global.

A constituição de grupos de discussão com a seleção de jovens de cada turma, neste caso concreto seis, permitiu que se conseguisse acesso às percepções dos mesmos sobre o conceito de indisciplina, sem a intervenção do adulto. Desse modo, acedeu-se a 
informação privilegiada, o que permitiu um claro entendimento das suas preocupações, sensações e até sugestões sobre o conceito e o seu combate em contexto escolar.

Foram também consultados os procedimentos disciplinares realizados no ciclo em análise, sendo o resultado dessa análise explicitado numa tabela com os elementos descriminados de seguida: número de processos; medidas disciplinares sugeridas pelo aplicador do processo; e ainda a reincidência dos alunos.

\section{Resultados e discussão}

A análise dos resultados e a sua discussão é feita a partir da reflexão sobre a forma como as medidas implementadas pelo agrupamento de escolas no combate à indisciplina estão interligadas ao seu desenvolvimento, procurando estabelecer uma relação entre a burocracia subjacente à implementação das medidas legais e sua não utilização; refletir sobre como a não utilização desses mecanismos formais aumenta a utilização de mecanismos de remediação reativos; e, ainda, se a falta de uniformização de medidas de combate à indisciplina leva a um aumento da mesma.

Se tomarmos como ponto de partida a entrevista com o diretor do agrupamento, verificamos um antagonismo patente na tomada de medidas de combate à indisciplina. Se, por um lado, implementa escrupulosamente a legislação em vigor, mais tarde, no decorrer da entrevista, classifica-a como "morosa e não adequada à realidade escolar" e reitera a necessidade de a escola precisar de "mais autonomia no âmbito da implementação das medidas disciplinares”. Essa situação é, aliás, corroborada pela coordenadora dos diretores de turma, quando menciona que as medidas aplicadas não são eficazes no tratamento da indisciplina. Além disso, a coordenadora dos diretores de turma refere o esforço na tentativa de aplicação da legislação, mas que os docentes ao não “[...] cumprirem a sua parte, nomeadamente na marcação de faltas disciplinares e participações, não contribuem para a resolução do problema”. Também os diretores de turma são unânimes ao apontar a burocracia inerente às medidas como um entrave à utilização de mecanismos legais.

Em concordância com essa afırmação, os alunos nos grupos de discussão salientaram que a maior parte das participações disciplinares acaba por ser esquecida ou negociada com o diretor de turma e que, mesmo que venham a ser castigados, esse castigo acontece bastante mais tarde e, normalmente, são apenas repreendidos.

Se atentarmos à pesquisa documental, verificamos um número de 123 participações disciplinares, algumas delas de cariz extremamente gravoso, como por exemplo, ameaças a docentes e agressões verbais em contexto de sala de aula; e que numa turma do sexto ano existem 21 participações disciplinares, todas do mesmo aluno. Se cruzarmos esses dados com o número de procedimentos disciplinares realizados, verifica-se que apenas três alunos foram alvo de sanções após os mesmos, visto que num dos processos os fatos não foram dados como provados, fica patente a ineficácia das medidas implementadas na atenuação da indisciplina, bem como o fato da extrema burocracia associada a qualquer sanção disciplinar.

Essa situação tem sido apontada e salientada na literatura relacionada com a necessidade de mais autonomia das escolas no âmbito do combate à indisciplina e a 
possibilidade de aplicação de sanções de forma coerente, ágil e sem permissividade. Além disso, é frequente a associação das políticas escolares e a organização escolar como responsáveis pelo desenvolvimento do mau comportamento dos alunos (FERRINHO, 2012, p. 42), ou, ainda, como causas da indisciplina, os regulamentos disciplinares, a falta de homogeneidade das regras estabelecidas e das sanções (FERRINHO, 2012, p. 47). Em consonância com esta autora, também Renca (2008, p. 207) refere que um dos principais entraves à aplicação de sanções disciplinares é a morosidade do processo e a burocracia associada ao ele.

Os dados relevam que as medidas levadas a cabo pelo agrupamento em estudo no combate à indisciplina contribuem para o seu aumento; a excessiva carga burocrática, 0 consequente tardar das sanções e o caráter reativo das soluções desenvolvidas leva a que a indisciplina continue a aumentar. Também a ineficácia das medidas, como se verifica pelo número de participações disciplinares e a quantidade de procedimentos disciplinares realizados, leva a um descrédito da organização no âmbito em estudo, conduzindo a um sentimento de liberdade nos alunos indisciplinados.

Além disso, e como consequência direta da afirmação anterior, prova-se, em consonância, que a burocracia inerente à aplicação de sanções disciplinares exerce influência na indisciplina. Através dessa análise, considera-se estabelecido que a burocracia existente no agrupamento de escolas em estudo acaba por levar a um abandono da aplicação das medidas legais, reduzindo a sua utilização e proporcionando, assim, a percepção coletiva de um aumento da indisciplina.

Ao reduzir a utilização de mecanismos legais, pela sua morosidade e complexidade (nas palavras do diretor do agrupamento de escolas e de alguns diretores de turma), o agrupamento sente a necessidade de implementar mecanismos de apoio no combate à indisciplina, o que leva ao surgimento de mecanismos à margem da legislação, que muitas vezes assume caráter de normas não formais, apenas partilhadas por um grupo restrito de atores, como, por exemplo, quando se negociam participações disciplinares ou se castigam os alunos à margem do sistema. Essas medidas poderão resultar no instante da aplicação, no entanto, a longo prazo são ineficazes e causadoras de descrédito do sistema de combate à indisciplina. Ainda dentro desse campo de análise, verifica-se pela análise das atas dos conselhos de turma uma grande ênfase em medidas de remediação: contato com os encarregados de educação pelo meio mais expedito; maior frequência de contatos entre o encarregado de educação e o diretor de turma; envio do aluno para a biblioteca com tarefas a executar; comunicação ao diretor de turma e ao encarregado de educação, por parte do professor, das atitudes do aluno.

No entanto, em três turmas analisadas, surgem explícitas as indicações para a elaboração de um relatório semanal por parte do delegado de turma, a ser analisado em educação cívica, e coadjuvação em sala de aula, que se destacam pela sua proatividade, contudo, em muito menor escala que as anteriores.

Também salienta-se, devido ao seu caráter proativo, a intenção do agrupamento de criar um código de conduta, perseguindo o objetivo de uniformizar critérios de atuação neste e noutros campos, a ser respeitado por todos os atores educativos internos. Esse código de conduta deverá estar elaborado e aplicado no início do próximo ano letivo, 
levando a uma maior uniformização de critérios e a uma união, entre outros aspectos, no combate à indisciplina.

Ainda assim, neste momento, os resultados são claros quanto ao descrédito dos mecanismos legais que têm levado ao incremento da utilização de mecanismos reativos à indisciplina e não de uma estratégia concertada de combate à mesma. A exemplo do proposto em Amado (2001) e Carita e Fernandes (1997) que apontam para o desenvolvimento de estratégias proativas no processo de atenuação e/ou erradicação da indisciplina.

Os resultados indicam que a falta de uniformização de medidas de combate à indisciplina na sala de aula, por parte dos docentes, leva ao seu aumento. Verifica-se que existem docentes a entregar um elevado número de participações disciplinares, enquanto outros não entregam nenhuma ao longo do ano. Os próprios alunos, quando questionados acerca dessa questão, chegam a admitir que com o professor J, com o professor A ou, ainda, com a professora B não se atrevem a se comportar de forma inadequada, salientando a existência de conversas em privado, conversas que nunca existiram, mas que assumem como histórias verdadeiras do agrupamento. No entanto, as estratégias praticadas por esses docentes funcionam em suas aulas, mas assumem-se como prejudiciais no cômputo geral do agrupamento, visto que significam uma ruptura numa estrutura mais abrangente que deveria existir no combate ao fenômeno em estudo, fazendo com que os alunos desrespeitem os docentes que não se enquadrem no perfil-tipo do docente respeitado. Ainda dentro desse contexto, e sustentando a afirmação acima, verifica-se que os professores selecionados para coadjuvação em sala de aula são, sempre que disponíveis, os docentes respeitados, o que enfraquece ainda mais a posição dos docentes titulares da turma. Ferrinho (2012, p. 183) e Teixeira (2013, p. 76) afırmam que a falta de convergência na atuação dos professores é um dos principais fatores propiciatórios do desenvolvimento da indisciplina.

As diferentes fontes de informação trabalhadas são consistentes na apreciação de que no agrupamento de escolas em análise as medidas de combate à indisciplina, apesar de apoiadas nos normativos em vigor, são ineficazes devido, em grande parte, à burocracia que lhes é subjacente, ao surgimento de estratégias de remediação, meramente reativas e que, por conseguinte, apenas surtem um efeito parcelar, anulando comportamentos e não agindo contra a globalidade do fenômeno. Como tal, apesar do investimento de todos os atores educativos, a indisciplina continua a persistir. Atribui-se a persistência de fenômenos de indisciplina a fatores internos ao agrupamento e também a fatores externos, tal como o meio ou a comunidade. Esses fatores, descritos no corpo do artigo, poderão ser enfraquecidos mediante um maior investimento numa perspectiva de caráter proativo de combate à indisciplina, numa maior coordenação entre o meio e a escola, como sustenta Chaves (2013), integrado na nova perspectiva organizacional da mesma e de uma uniformização de procedimentos a adotar pelos atores, visando uma ação concertada e planificada.

Como tal, sugere-se, em seguida, um conjunto de medidas com o intuito de auxiliar o agrupamento nesse campo, no futuro:

- investimento na desburocratização da implementação das medidas legais aplicadas à indisciplina, que torne o processo mais célere, transparente e eficaz, fornecendo, desse modo, à comunidade docente um mecanismo eficaz de combate à indisciplina e que auxilie 
na sua atenuação, promovendo uma atuação concertada e eficaz e uma uniformização de procedimentos;

- investimento em medidas proativas de combate à indisciplina, tais como a criação do código de conduta ou a implementação de um gabinete de combate à indisciplina que promova ações de formação e atividades a fim de sensibilizar os alunos para o problema;

- fomento da formação dos professores no âmbito da mediação de conflitos, tão necessária na visão social atual e no consequente novo paradigma do processo de ensino/ aprendizagem;

- desvalorização dos comportamentos e ações marginais dos docentes e uma preocupação no combater à indisciplina de forma concertada e planificada, mediante o estabelecimento de objetivos claros e definidos para a prossecução da erradicação do fenômeno;

- por último, que promova a interação entre os atores externos e internos na figura dos encarregados de educação, Projeto Escola Segura, docentes, alunos, entre outros, na dinamização de uma cultura de responsabilização e de proatividade no combate à indisciplina.

\section{Referências}

AMAD0, João. Interacção pedagógica e indisciplina na aula. 1. ed. Lisboa. Asa. 2001. (Perspectivas actuais).

ANTONUCCI, Raquel; LONGO, Cristiano. Emergência e evolução do conceito de indisciplina escola. Pesquisa em Debate, São Paulo, v. 4, n. 1. p. 1-14, 2007. Disponível em: <http://www.pesquisaemdebate.net/docs/ pesquisaEmDebate_6/artigo_4.pdf>. Acesso em: 27 jul. 2018.

BANALETTI, Samara; DAMETTO, Jarbas. Indisciplina no contexto escolar: causas, consequências e perspectivas de intervenção. Revista de Educação do IDEAU, Getúlio Vargas, v. 10, n. 22. p. 15. 2015. Disponível em: <https://www.ideau.com.br/getulio/restrito/upload/revistasartigos/284_1.pdf>. Acesso em: 10 ago. 2018.

BOGDAN, Robert; BIKLEN, Sari. Investigação qualitativa em investigação: uma introdução à teoria e aos métodos. Porto. Porto Editora. 1994. (Ciências da educação).

CARITA, Ana; FERNANDES, Graça. Indisciplina na sala de aula: como prevenir? Como remediar? v. 5. 1. ed. Viseu. Presença, 1997. (Ensinar a aprender).

CARVALHO, Marisa et al. (In)disciplina na escola: para uma prática integrada e sustentada de intervenção. In: PALMEIRÃO, Cristina; ALVES, José Matias (Coord.). Promoção do sucesso educativo: estratégias de inclusão, inovação e melhoria. Porto: Universidade Católica, 2016. p. 119-143. Disponível em: <http://www.uceditora. ucp.pt/resources/Documentos/UCEditora/PDF\%20Livros/Porto/E-Book_Promo\%C3\%A7\%C3\%A30\%20 Do\%20Sucesso_Final.pdf>. Acesso em: 3 jun. 2019.

CHAVES, Graça. Estudo de caso sobre as dinâmicas organizacionais na resolução da indisciplina. 2013. Dissertação (Mestrado em Administração Pública) - Universidade de Lisboa, Lisboa, 2013. Disponível em: <https:// www.repository.utl.pt/bitstream/10400.5/6557/1/Disserta\%C3\%A7\%C3\%A30\%20Mestrado\%20 Gra\%C3\%A7a\%20Chaves.pdf>. Acesso em: 29 jul. 2018. 
ESTRELA, Maria Teresa. Relação pedagógica, disciplina e indisciplina na aula. 4. ed. Porto: Porto Editora, 2002.

FERRINHO, Maria Teresa Nunes. Indisciplina na sala de aula: que realidade? (estudo exploratório). 2012. Dissertação (Mestrado em Ensino da Matemática) - Universidade Lusíada, Lisboa, 2012. Disponível em: $<$ http://repositorio.ulusiada.pt/bitstream/11067/532/1/mm_maria_ferrinho_dissertacao.pdfAcesso em: 28 jul. 2018.

KRIPKA, Rosana; SCHELLER, Morgana; BONOTTO, Danusa. Pesquisa documental na pesquisa qualitativa: conceitos e caracterização. Revista de Investigaciones Unad, Bogotá, v. 2. n. 14, p. 55-73, 2015. Disponível em: <http://hemeroteca.unad.edu.co/index.php/revista-de-investigaciones-unad/article/ viewFile/1455/1771>. Acesso em: 27 jul. 2018.

OLIVEIRA, Maria Izete de. Factores psico-sociais e pedagógicos da indisciplina: da infância à adolescência. Linhas Críticas, Brasília, DF, v. 14, n. 27, p. 298-305, 2009b. Disponível em: <http://periodicos.unb.br/ index.php/linhascriticas/article/viewFile/7485/5790>. Acesso em: 14 jul. 2018.

OLIVEIRA, Rosimary Lima Guilherme. Reflexões sobre a indisciplina a partir da sua diversidade conceptual. In: CONGRESSO NACIONAL DE EDUCAÇÃO (EDUCERE), 9., 2009, Curitiba. Anais..., Curitiba: [s. n.], 2009a. Disponível em: <http://educere.bruc.com.br/arquivo/pdf2009/3412_1708.pdf>. Acesso em: 23 jul. 2018. p. 4503-4514.

PALMA, Cristina. Formação de professores na e a prevenção da indisciplina. 2011. Dissertação (Mestrado em Ciências da Educação) - Escola Superior de Educação Almeida Garrett, Lisboa, 2011. Disponível em: <http://recil.grupolusofona.pt/bitstream/handle/10437/1702/Disserta\%C3\%A7\%C3\%A30_Cristina\%20 Palma.pdf?sequence=1>. Acesso em: 28 jul. 2018.

PEREIRA, Amélia Neves. (In)disciplina na aula: uma revisão bibliográfica de autores portugueses. Revista Lusófona de Educação, Lisboa, n. 5, p. 193-198, 2005. Disponível em: <http://www.scielo.mec.pt/scielo. php?script=sci_arttext\&pid=S1645-72502005000100013\&lng=pt\&nrm=iso>. Acessos em: 15 ago. 2018.

PINTO, Sónia Cristina Vieira. Indisciplina na sala de aula: a perspetiva de professores do ensino básico e do ensino secundário. 2014. Dissertação (Mestrado em Ciências da Educação) - Escola Superior de Educação de Lisboa, Lisboa, 2014. Disponível em: <https://repositorio.ipl.pt/bitstream/10400.21/3943/1/ Indisciplina\%20na\%20sala\%20de\%20aula.pdf>. Acesso em: 14 jul. 2018.

PORTUGAL. Lei n. ${ }^{\circ}$ 51/2012, de 5 de setembro - Aprova o Estatuto do Aluno e Ética Escolar, que estabelece os direitos e os deveres do aluno dos ensinos básico e secundário e o compromisso dos pais ou encarregados de educação e dos restantes membros da comunidade educativa na sua educação e formação, revogando a Lei n. 30/2002, de 20 de dezembro. Lisboa: [s. n.], 2012a. Disponível em: <http://data.dre.pt/eli/ lei/51/2012/09/05/p/dre/pt/html>. Acesso em: 27 jul. 2018.

PORTUGAL. Lei n. ${ }^{\circ}$ 137/2012, de 2 de julho - segunda alteração do Decreto-Lei n. ${ }^{0}$ 75/2008, de 22 de abril, que aprova o regime jurídico de autonomia, administração e gestão dos estabelecimentos públicos da educação pré-escolar e dos ensinos básico e secundário. Lisboa: [s. n.], 2012b. Disponível em: <https:// dre.pt/web/guest/pesquisa/-/search/178527/details/normal?|=1>. Acesso em: 5 mar. 2019. 
PORTUGAL. Parecer $n^{0}$. 3/2002, de 31 de janeiro, do Conselho Nacional de Educação - Para Combater a Indisciplina nas Escolas. Lisboa: [s. n.], 2002. Disponível em: <http://www.cnedu.pt/content/antigo/files/ cnepareceresmodule/Parecer_3_2002.pdf>. Acesso em: 5 mar. 2019.

RENCA, António André. A Indisciplina na sala de aula: percepções de alunos e professores. 2008. Dissertação (Mestrado em Ciências da Educação) - Universidade de Aveiro, Aveiro, 2008. Disponível em: <https://ria. ua.pt/bitstream/10773/1045/1/2009001357.pdf>. Acesso em: 29 jul. 2018.

RODRIGUES, Icaro Arcênio de Alencar; MARQUES, Larissa Carvalho; GOMES, Márcia Maria Costa. Como a indisciplina em sala de aula interfere no trabalho docente. Revista Principia, João Pessoa, n. 21, p. 21 29, 2012. Disponível em: <periodicos. ifpb.edu.br/index.php/principia/article/download/156/126>. Acesso em: 14 jul. 2018.

SILVA, Isabel; VELOSO, Ana Luísa; KEATING, José. Focus group: considerações teóricas e metodológicas. Revista Lusófona de Educação, Lisboa, n. 26, p. 175-190, 2014. Disponível em: <https://www.dge.mec. pt/sites/default/files/EPIPSE/in_disciplina_na_escola_para_uma_pratica_integrada_e_sustentada_de_ intervencao.pdf>. Acesso em: 28 jul. 2018.

TEIXEIRA, Celestino Tomás Tavares. A indisciplina na sala de aula: um estudo centrado numa escola caboverdiana. 2013. Dissertação (Mestrado em Administração das Organizações Educativas) - Escola Superior de Educação do Porto, Porto, 2013. Disponível em: <http://recipp.ipp.pt/ bitstream/10400.22/7926/1/DM_CelestinoTeixeira_2013.pdf>. Acesso em: 28 jul. 2018.

Recebido em: 22.08.2018

Revisado em: 12.02.2019

Aprovado em: 19.03.2019

José Sousa Santos é professor do ensino básico e professor especializado em administração e organização escolar na área da administração escolar e educacional da Escola Superior de Educação de Fafe.

João Carlos Pascoinho é professor adjunto no Instituto de Estudos Superiores de Fafe e professor coordenador do curso de formação especializada em administração e organização escolar da Escola Superior de Educação de Fafe. 